\title{
Disentangling The Thick Concept Argument
}

\section{Olle Blomberg}

\begin{abstract}
Critics argue that non-cognitivism cannot adequately account for the existence and nature of some thick moral concepts. They use the existence of thick concepts as a lever in an argument against non-cognitivism, here called the Thick Concept Argument (TCA). While TCA is frequently invoked, it is unfortunately rarely articulated. In this paper, TCA is first reconstructed on the basis of John McDowell's formulation of the argument (from 1981), and then evaluated in the light of several possible non-cognitivist responses. In general, TCA assumes too much about what a non-cognitivist is (or must be) committed to. There are several non-cognitivist theories, and only some fit the view attacked by TCA. Furthermore, TCA rests on a contestable intuition about a thought experiment, here called the External Standpoint Experiment (ESE). It is concluded that TCA is remarkably weak, given how frequently the argument is invoked.
\end{abstract}

Keywords: thick concepts, moral concepts, non-cognitivism, disentangling, John McDowell, Simon Blackburn

\section{Introduction}

Philosophers tend to look for particular words as marks of morality at work: 'good', 'treacherous', 'promise', 'just', 'cruel', 'ought', 'honest', and so on. The concepts corresponding to these words can be distinguished according to their degree of descriptive content. On the one hand, we have our most general thin moral concepts, think of 'good', 'bad', 'right', 'wrong' and 'ought'. On the other hand, we have the less domain-general thick moral concepts like 'treacherous', 'rude', 'cruel', and 'honest'. I will simply call these two classes of moral concepts "thin concepts" and "thick concepts", leaving out "moral" from now on.

Thick concepts appear to cause trouble for non-cognitivism because, in the words of Bernard Williams, they "seem to express a union of fact and value" (1985, p. 129). Such a union threatens an apparently central assumption of non-cognitivism, namely that a clear distinction can be drawn between evaluative and non-evaluative language. For example, Alfred Ayer's emotivism (2001[1936]) rests on a sharp distinction between a moral and a non-moral 
vocabulary. ${ }^{1}$ Some later non-cognitivists, like Charles Stevenson and Richard Hare, have instead drawn the distinction at an underlying level of meaning components. On their view, the meaning of a thick concept can be unpacked in roughly the following way: 'This is $\mathrm{X}$ ', where $\mathrm{X}$ is a thick moral concept, means "This has the purely descriptive qualities or relations A, B, C, ..., and I (dis)approve of $\mathrm{X}$ because of $\mathrm{A}, \mathrm{B}, \mathrm{C}, \ldots . .{ }^{\prime 2}$ Hence, a purely descriptive meaning component can be disentangled from the meaning of the concept as a whole, leaving out the approval or disapproval.

Well-known contemporary non-cognitivists like Allan Gibbard (1990, 1992) and Simon Blackburn $(1981,1992,1998)$ reject Hare's two-component analysis. They do not arrive at non-cognitivism from a commitment to a particular view of lexical meaning but rather from a commitment to a Galilean naturalism.

However, critics argue that non-cognitivists, regardless of the particular type of analysis they employ, cannot adequately account for the existence and nature of some thick concepts. I call these critics Entanglers. They use the existence of thick concepts as a lever in an argument against non-cognitivism that I call the Thick Concept Argument or TCA. The argument originates in John McDowell's writings from the late 70s and early $80 \mathrm{~s}$. Bernard Williams later connected McDowell's line of thought with his own notion of thick concepts (1985, pp. 141-142). In recent years, TCA has been invoked, for example, by Hilary Putnam in 2002 (ch. 2), by Alice Crary in 2002 (pp. 389-390), and by Charles Taylor in 2003 (p. 306). Unfortunately, while TCA is frequently invoked, the argument is rarely articulated.

I do two things in this paper. First, in section 1, I articulate what I take to be the most charitable interpretation of TCA, based on McDowell's presentation of the argument in (1981). Then, in section 2, I critically evaluate the argument and show how non-cognitivists can defend themselves against it. In light of the available non-cognitivist responses, I conclude in the third and final section that TCA is remarkably weak, given how frequently it is invoked.

TCA is often inadequately presented simply as a stubborn objection against the two-component analysis itself (see, for example, Altham 1986, Burton

1 Ayer (2001[1936]) treats thick concepts either as thin moral concepts or as purely descriptive concepts. For an example of the former, see his statement about 'beautiful' and 'hideous' (p. 118). For signs of the latter, see his analyses of moral statements such as "Thrift is a virtue", "Stealing money is wrong", and "Tolerance is a virtue" where he does not notice that 'thrift', 'stealing' and 'tolerance' are value-laden concepts (pp. 110, 112, 114).

2 This type of paraphrase captures both Stevenson's "second pattern of analysis" (1948), and Hare's characterisation of "secondarily evaluative terms" (1970[1952]). 
1992, Millgram 1995, Putnam 2002). Since it is far from obvious why noncognitivists need to adopt such an analysis, this makes TCA look ridiculous. My reconstruction of TCA (section 1) on the other hand, makes it clear that the argument is intended both to show that a two-component approach is inadequate in some cases and to show that non-cognitivists must take this inadequate approach in order to honour a commitment to treat moral discourse as rational (a commitment most contemporary non-cognitivists embrace).

\section{The Thick Concept Argument}

I will now present what I take to be the most charitable interpretation of TCA. ${ }^{3}$ The presentation is solely based on what I take to be the most accomplished articulation of TCA available, found in McDowell's 'Non-Cognitivism and Rule-Following' from 1981 (also see McDowell 1978, 1979). Note that McDowell never uses the concept of thick concepts, but many authors have pointed out McDowell as the original source of TCA. ${ }^{4}$ Thus, my reading of 'Non-Cognitivism and Rule-Following' is based on the assumption that McDowell is there presenting an argument that is connected with the existence of thick concepts.

McDowell describes what he takes to be the central feature of non-cognitivism in the following way:

Typically, non-cognitivists hold that when we ascribe value to something, what is actually happening can be disentangled into two components. Competence with an evaluative concept involves, first, a sensitivity to an aspect of the world as it really is (as it is independently of value experience), and second, a propensity to a certain attitude - a non-cognitive state which constitutes the special perspective from which items in the world seem to be endowed with the value in question. (McDowell 1981, p. 143)

According to McDowell, this type of two-component analysis requires that

corresponding to any value concept, one can always isolate a genuine feature of the world - by the appropriate standard of genuineness: that is, a feature that is there anyway, independently of anyone's value experience being as it is - to be that which competent users of the concept are to be regarded as responding when they use it [...] (McDowell 1981, p. 144)

3 See Millgram (1995) for various other interpretations of TCA.

4 For example Bernard Williams (1985, pp. 217-218n7), Hilary Putnam (2002, pp. 38-39), Charles Taylor (2003, p. 306), James Altham (1986, p. 278n6), and Elijah Millgram (1995, sect. 2). Gerald Lang (2001) and Alexander Miller (2003), on the other hand, read McDowell's 1981 paper without ever making the connection with thick concepts that I make here. 
With "a genuine feature of the world," it is clear that McDowell means a genuine kind of the world. McDowell's characterisation of the non-cognitivist's conception of genuine kinds plays an important role in TCA. It is unfortunate then, that the characterisation is not more precise (and McDowell does not provide any examples of kinds that fit the conception). The conception clearly rules out genuine kinds that have intrinsic value or motivating force, however. He mentions John Mackie and Hare as examples of moral philosophers who embrace the non-cognitivist conception (McDowell 1981, p. 159n6). ${ }^{5}$ The non-cognitivists' genuine kinds - in McDowell's view - seem to be kinds that figure in a natural scientific framework, in what Gibbard calls "the Galilean core." This is "our rough story of how, ultimately, a wide range of things are matters of fundamental physics" (Gibbard 1990, p. 123). It is a framework that can be used to explain the natural world, including, speculatively, the makeup and behaviour of its moral agents (their applications of thick concepts, for example). Thus, I will use the term Genuine Natural Kind, or GNK, to refer to those kinds that are in line with what McDowell takes to be the non-cognitivist's "appropriate standard of genuineness."

A competent user of a moral concept must, according to McDowell's characterisation of non-cognitivism, respond to the same kind of natural thing, from one application to the next. This requires, according to McDowell, that it is in principle possible to "disentangle" a purely descriptive meaning that picks out the GNK from the value concept's meaning. The requirement is sometimes expressed by saying that moral concepts have descriptive or natural shape. If a moral concept would be descriptively or naturally shapeless, then its descriptive meaning would be open-endedly disjunctive.

Hare's two-component approach certainly fits this characterisation. In the case of Hare, the two-component approach is not only taken to account for thick concepts but also to develop an account of moral rationality. The descriptive meaning of a concept is construed by Hare as a rule of application. If speakers want to make sense to one another when using a concept, then they have to follow its rule of application. That is, they have to keep applying the concept to things that are all of the same kind (see Hare's discussion of 'red' in 1963, p. 11). This kind is what McDowell calls "a genuine feature of the world," and what I refer to as a GNK. When one makes a moral judgement, say ' $\mathrm{X}$ is courageous', then the descriptive meaning of 'courageous' picks out a kind of behaviour that the evaluative meaning of the judgement latches on

5 See Mackie (1977, p. 40). While Mackie may embrace a non-cognitivist conception of genuine kinds, he rejects the non-cognitivist conception of moral judgements. 
to (the approval typically attached to 'courageous'). When we use evaluative words, our evaluations attach to certain kinds of the world and are thereby universalized. ${ }^{6}$

With this conception of moral rationality and consistency in mind, McDowell further argues that while non-cognitivists may acknowledge that "disentangling" is impossible in some cases, they

[...] can do so only at a price: that of making it problematic whether evaluative language is close enough to the usual paradigms of concept-application to count as expressive of judgements at all (as opposed to a kind of sounding off). (McDowell 1981, p. 158)

Of course, non-cognitivists do not treat evaluative language exactly as "the usual paradigms of concept-application," but they typically try to show that evaluative language inherits some properties of descriptive language that let us treat it as "a matter of the genuine application of concepts" (McDowell 1981, p. 157). At least Hare, Gibbard, and Blackburn work hard to make a non-cognitivist view of moral language compatible with its descriptivelooking surface.

Non-cognitivists do not need to argue that the application of all moral concepts is a matter of genuine concept-application, however. While some moral concepts are genuine, the application of many moral "concepts" may indeed be better thought of as "a kind of sounding off." I will call the non-empty set of moral concepts whose application must be construed as genuine the set $G$, and the genuine moral concepts I will call G-members.

We can now formulate the first two premises of TCA in the following way:

(P1) The application of every G-member is genuine and G is a nonempty set.

(P2) If non-cognitivism is true, then a genuine application of a concept picks out a GNK.

If a moral concept corresponds to a GNK, then this implies, according to McDowell, that its extension can be mastered from "the external standpoint" (McDowell 1981, p. 155). This standpoint is the standpoint of someone observing a moral community from the outside; imagine an anthropologist observing

6 According to Van Roojen (2005), similar explanations of how relations of (in)consistency can hold between moral judgements have been proposed by Frank Jackson (1999) and Stephen Barker (2000). 
an alien moral community in an extremely disengaged way. McDowell asks us to consider the following thought experiment (also see Williams 1985, pp. 141-142):

Consider, for instance, a specific conception of some moral virtue: the conception current in a reasonably cohesive moral community [i.e. a thick concept]. If the disentangling manoeuvre is always possible, that implies that the extension of the associated term, as it would be used by someone who belonged to the community, could be mastered independently of the special concerns which, in the community, would show themselves in admiration or emulation of actions seen as falling under the concept. That is: one could know which actions the term would be applied to, so that one would be able to predict applications and withholdings of it in new cases - not merely without oneself sharing the community's admiration (there need be no difficulty about that), but without even embarking on an attempt to make sense of their admiration. That would be an attempt to comprehend their perspective; whereas, according to the [noncognitivist] position I am considering, the genuine feature to which the term is applied should be graspable without benefit of understanding the special perspective, since sensitivity to it is singled out as an independent ingredient in a purported explanation of why occupants of the perspective see things as they do. But is it at all plausible that this singling out can always be brought off? [Is it plausible that this singling out can be brought off for every thick concept?] (McDowell 1981, p. 144)

I will refer to this thought experiment as the External Standpoint Experiment (ESE), and I will call the observer Theo (The external observer). Whenever I refer to Theo, I implicitly invoke the situation that he faces in ESE. The point of ESE is to raise scepticism about the idea that it is possible to disentangle a purely descriptive component (that can pick out a GNK) from the meaning of every thick concept. For the argument to work, McDowell must claim that at least one of the concepts whose extension Theo cannot master, is a G-member.

We may now formulate the remaining two premises of TCA in the following way:

(P3) If the application of a concept picks out a GNK, then it is in principle possible for Theo to master the concept's extension.

(P4) There exists at least one G-member whose extension Theo cannot master even in principle.

Note that ESE is a purely hypothetical thought experiment, McDowell is not saying that anyone is ever in the position of Theo. Neither is he saying that non-cognitivists claim that anyone is in this position. The claim is merely that 
if non-cognitivism is true, then Theo, whether real or imaginary, must be able to master the extensions of all G-members.

If TCA is sound, then non-cognitivists are forced to either (1) insist that all G-members can be disentangled (that is, reject P4), or (2) bar themselves from treating the application of some G-members as genuine. The dilemma is this: The non-cognitivist cannot choose the former (1), since it contradicts the purported "results" of ESE, nor the latter (2), since he is committed to construing moral discourse involving G-members as genuine discourse.

The premises P1, P2, P3 and P4 are all we need to arrive at the argument's conclusion with the following steps:

(M1) The application of at least one G-member does not pick out a GNK. [Modus tollens, P3 \& P4]

(M2) If non-cognitivism is true, then the application of at least one

G-member is not genuine. [Modus tollens, P2 \& M1]

(C) Non-cognitivism is not true. [Modus tollens, M2 \& P1] ${ }^{7}$

TCA obviously hinges on a certain picture of non-cognitivism. McDowell assumes that the non-cognitivist readily accepts P1, P2 and P3. Hence, he is primarily trying to persuade his readers to accept $\mathrm{P} 4$, which he sees as the argument's crucial and contentious premise. ESE is used by McDowell (and his fellow Entanglers) as an "intuition pump" to undermine resistance to P4. ${ }^{8}$

McDowell also uses a particular interpretation of Wittgenstein's "rulefollowing considerations" in order to get us to accept P4. ${ }^{9}$ However, this use of the rule-following considerations has been strongly criticized (see Miller

7 The argument can be formalised in the following way:

P1. $\forall x(x \in \mathrm{G} \rightarrow \mathrm{GA}(x)) \wedge(\mathrm{G} \neq \varnothing)$

P2. noncog $\rightarrow \forall x(\operatorname{GA}(x) \rightarrow \operatorname{GNK}(x))$

P3. $\forall x(\operatorname{GNK}(x) \rightarrow \operatorname{THEOME}(x))$

P4. $\exists x(x \in \mathrm{G} \wedge \neg \mathrm{THEOME}(x))$

M1. $\exists x(x \in \mathrm{G} \wedge \neg \mathrm{GNK}(x))$

M2. noncog $\rightarrow \exists x(x \in \mathrm{G} \wedge \neg \mathrm{GA}(x))$

C. $\neg$ noncog

8 See Dennett (1995) on intuition pumps and arguments.

9 McDowell asserts that "one strand in Wittgenstein's thought about 'following a rule' is that the source of the temptation [to think that there 'must' be genuine feature of the world regulating our use of a concept] is the desire for a security which is actually quite illusory" (1981, p. 145). Williams writes that "[t]he idea that it might be impossible to pick up an evaluative concept unless one shared its evaluative interest is basically a Wittgensteinian idea" (1985, p. 217-218n7). 
2003; Millgram 1995; Koons 2001; Lang, 2001). While there is an alleged connection between P4 and the rule-following considerations, I believe that TCA is best understood as independent of them. First of all, the rule-following considerations are considerations that bear on how to think about language and meaning in general, while ESE questions the way the meaning of some particular thick concepts can be analysed. Secondly, while the rule-following considerations may support P4, they seem to undermine P3, thus making them incompatible with TCA(Lang 2001, p. 203). The rule-following considerations show that even if Theo knows that a concept has been consistently applied to a certain GNK previously, this does not guarantee that Theo would be able to master the concept's extension, since the history of the concept's use does not determine its future use. I will not discuss McDowell's use of the rulefollowing considerations further in this paper.

Before moving on to non-cognitivist responses to TCA, I want to clarify the connection between TCA and Williams' notion of thick concepts. Entanglers typically treat some of our thick concepts as the most basic moral concepts, while they take thin moral concepts ('ought' or 'good' for example) to be dependent on a repertoire of thick concepts (for example, see Anderson 1993, sect. 5.2; Hurley 1983; Lovibond 1983, p. 14). They are typically realists with regard to the application of thick concepts, but not obviously with regard to thin concepts (see McDowell 1998, pp. 151-152). Hence, according to Entanglers, some thick concepts ought to be prototypical G-members. Perhaps Entanglers also think that thick concepts are the most obvious candidates of naturally shapeless concepts. While purely descriptive words may be highly polysemous, they are not obviously best construed as corresponding with only one concept. But thick concepts on the other hand are shapeful according to Entanglers, just not naturally shapeful.

\section{Non-Cognitivist Evasive Manoeuvres}

I will now shoehorn five well-known non-cognitivists into the frame provided by my reconstruction of TCA and show how they can avoid the argument's conclusion. Given that my reconstruction is plausible, there are obviously four logically possible moves that non-cognitivists can make to avoid the argument. At least three of these moves have been made already by existing non-cognitivists. The following table shows what Ayer, Stevenson, Hare, Gibbard and Blackburn would say about P1, P2, P3 and P4. 


\begin{tabular}{|c|c|c|c|c|}
\hline Non-cognitivist & P1 & P2 & P3 & P4 \\
\hline Ayer/Stevenson & False & $?$ & $?$ & False \\
\hline Hare & True & True & True & False \\
\hline Gibbard & True & False & True & True? \\
\hline Blackburn & True & False & True & True/False \\
\hline
\end{tabular}

Table 1 Non-cognitivist responses to TCA.

\section{Ayer and Stevenson}

Ayer and Stevenson deny P1, as McDowell himself recognises (1981, p. 158, 162n28). According to Ayer, moral concepts are mere "pseudo-concepts" and moral judgements are "outside the scope of argument" (2001[1936], pp. 115116). Similarly, Stevenson claims that conflicts of interests can only be resolved by persuasion using non-rational (but not irrational) methods (1938, pp. 344350 ). With this manoeuvre, however, TCA is avoided only by flouting what is now a widely accepted desideratum on metaethical theories, namely that they can make sense of the idea that moral judgements can be correct or incorrect (Smith 1994, ch. 1). Furthermore, the manoeuvre is not very interesting since McDowell himself intends TCA to be directed against non-cognitivists who believe there are some G-members (McDowell 1981, p. 158, 162n28).

It is not clear what Ayer or Stevenson would say about P2 and P3.

\section{Hare}

Hare best fits McDowell's characterisation of the non-cognitivist. He accepts P1, P2 and P3 and he is one of the Entanglers' primary targets (McDowell 1981, p. 159n6, Williams 1985, chs. 7-8).

Hare rejects $\mathrm{P} 4$ by insisting that there is no thick concept whose extension Theo could not master (in principle). Hare intends to comment on Theo's prospects in ESE in the following passage:

It is often said that if we had just the descriptive meaning of 'kind' we might, indeed, be able to recognise examples of kind people in the existing descriptive sense of the word, but would be unable to extend or extrapolate its use to new and perhaps slightly different examples. This seems to me to be simply false. Suppose that I am a hard-bitten person [...], and can recognize the qualities that people call kind and esteem, but do not myself esteem them. And suppose that some new example is produced of a person who does not have exactly those qualities, but has qualities very like them, so that people who do 
esteem them are likely to esteem that person too, and call him kind. I can see no difficulty in my predicting that this is what they will do. In order to make this prediction I do not myself have to esteem the qualities or the person; I only have to be confident that they will. I find it surprising that people should rely on this very weak argument. (Hare 1997, p. 61)

Hare clearly does not understand TCA.

First, he simply assumes that there must be an "existing descriptive sense" of a thick concept when the very point of ESE is to show that there is not always such an existing sense (not to show that Theo may not be able to master a thick concept's extension with its existing descriptive sense). According to Hare, there is, or must be, some unifying descriptive feature that forms a base from which the hard-bitten person or Theo can extrapolate the future use of a thick concept. In effect, Hare uses ESE to support the idea that thick concepts have shape.

Secondly, Hare simply assumes that "the qualities that people call kind and esteem" are purely descriptive qualities. However, Entanglers deny that the qualities picked out by a thick concept are always purely descriptive. According to Entanglers, some thick concepts only have shape at an evaluative level as they pick out an evaluative quality.

Finally, Hare implicitly attributes to Entanglers the claim that Theo must accept the evaluation embedded in the observed community's thick concept in order to master the concept's extension. However, this attribution is either mistaken or in need of an explanation. When describing ESE, McDowell explicitly denies the claim that Hare attributes to Entanglers:

one could know which actions the term [corresponding with some thick concept] would be applied to [...] - not merely without oneself sharing the community's admiration (there need be no difficulty about that), but without even embarking on an attempt to make sense of their admiration. (1981, p. 144; my emphasis)

Williams also denies the claim. He stresses the possibility of what he elsewhere calls "the ethnographic stance" (1986, pp. 203-204):

An insightful observer can indeed come to understand and anticipate the use of the concept without actually sharing the values of the people who use it [...]. But in imaginatively anticipating the use of the concept, the observer also has to grasp imaginatively its evaluative point. (Williams, 1985, pp. 141-142)

However, it is not clear what the difference is between (a) accepting the evaluation embedded in a thick concept ("sharing the values"), and (b) grasping the thick concept's "evaluative point" imaginatively without accepting 
it, where (b) cannot amount to acquiring a purely descriptive equivalent of the concept. ${ }^{10}$ Hare's attribution is not entirely unwarranted until Entanglers provide a clear account of this difference.

There seems to be a stand-off between different intuitions regarding P4. The competing intuitions only furnish arguments acceptable to the already converted. However, I believe the burden of proof is Hare's, since the claim of his intuition is stronger than the claim of the Entanglers' intuition. He claims that a purely descriptive meaning can be disentangled from all thick concepts, while Entanglers merely claim that there is at least one G-member from which a purely descriptive meaning cannot be disentangled.

\section{Blackburn: Defusing Shapelessness}

Gibbard and Blackburn, like Hare, accept P1 and go to great lengths to understand how a naturalistic non-cognitivism can be compatible with a conception of moral discourse as answerable to reasons and arguments. They argue that they can embrace P1 but reject or disregard P2. While their conception of GNKs is clearly in line with McDowell's characterisation, they do not claim that evaluations (not even ideal ones) must map onto them: Yes, the application of some moral concepts must be construed as genuine (it must be possible to "go on doing the same thing" when applying them), but genuine conceptapplication does not need to pick out GNKs. ${ }^{11}$ Hence, some G-members may be shapeless but this is of no consequence for non-cognitivism.

In a sense, I think that Gibbard and Blackburn embrace P1 less wholeheartedly than Hare. The metaethical projects that Gibbard and Blackburn are engaged in starts from a naturalistic world view and are aimed at explaining moral discourse and thought from within this view. If moral judgements do not look quite as robust as some instance of genuine concept-application when viewed from a naturalistic Galilean standpoint, then so much the worse for moral judgements. However, both Gibbard and Blackburn argue that moral judgements remain robust after their Galilean inspection. They argue that an evolutionary and developmental story of the origin our moral capacities can explain why some degree of consistency is important, and some can also be justified by appeal to considerations of justice and impartiality (Blackburn 1981, p. 180, Gibbard 1990, pp. 284-291).

10 I am grateful to the anonymous reviewer who reminded me of this. See Altham 1986, pp. 277-280 and Millgram 1995, pp. 360-365 for discussions about how to understand Williams' notion of an evaluative point or perspective.

11 One could also say that Blackburn and Gibbard do not accept the dichotomy between genuine concept-application and "sounding off" that McDowell imputes on them. 
I agree with McDowell that if non-cognitivists accept P4, then they cannot, like Hare, piggyback consistency on top of GNKs (with regard to the application of shapeless concepts). What alternative conception of consistency and rationality is available to Blackburn and Gibbard then? Blackburn briefly describes his alternative conception in the following way:

I believe that we do require a conception of 'going on in the same way' in ethics, not in the sense that we demand that all the things to which we have a given attitude form one kind, but in the sense that it worries us if we cannot draw distinctions when we react differently. (Blackburn 1981, p. 170)

There are two differences between this conception and the one that McDowell claims non-cognitivists must embrace. First, there is a shift from a "demand" to a "worry", and secondly, a shift from correspondences between attitudes and GNKs to the idea that cases (situations, actions, characters) which differ in value must also differ in description. In other words, when the same (descriptive) shape recurs but we react differently, there is need for reflection and re-evaluation. But there is no need to demand that one type of reaction (applying the concept 'kind', say) cannot be elicited by different natural features in different cases. This "thin" conception of consistency follows from what I take to be an uncontroversial assumption that the moral weakly supervenes on the nonmoral. ${ }^{12}$

Since P2 is rejected, Gibbard and Blackburn can safely take an agnostic stance toward P3 and P4. However, Gibbard finds P4 plausible and Blackburn explicitly accepts that Theo cannot master the extension of some thick concepts in responses to both McDowell and Williams (Gibbard 1990, pp. 114-115, 1992, p. 270; Blackburn 1981, p. 167, 1986, p. 199, 1998, p. 96-99). According to Blackburn, Theo does not merely face a difficult practical problem in trying to discern a unifying descriptive feature of a thick concept, "there is no a priori reason to expect there to be a unifying feature" (1981, p. 167).

While Blackburn clearly believes that some thick concepts are shapeless, it is not clear how commonplace he believes shapelessness to be, or whether he believes that there are shapeless G-members. ${ }^{13}$ The only concepts that he

12 In other words, the assumption is that two cases cannot differ morally unless they also differ nonmorally. If this dependency relation holds in the actual world but not in all possible worlds, then the moral supervenes weakly on the nonmoral. If it also holds in all possible worlds, then the moral supervenes strongly on the nonmoral.

13 Crary (2002, p. 390n38) claims that Blackburn's view of thick concepts changed between (1981), when he embraced P4, and (1992), when he rejected P4. I think his view remained the same, however. In any case, he clearly embraces P4 in (1998, p. 98). 
explicitly claims to be shapeless are 'funny', 'divine', and 'gross' (1998, pp. 96-98). When it comes to 'fat $\downarrow$ ' ('fat' delivered in "a characteristic sneering tone of voice"), "pejorative racial slurs", 'cruel', and 'courageous' on the other hand, Blackburn believes that they have shape. ${ }^{14}$ In the following passage, Blackburn seems to say that most thick concepts have descriptive or natural shape:

Whenever there is a 'thick' term it is easy to see both its general descriptive orientation, and its general practical or attitude-giving one. [...] We know that someone described as courageous is usually approved of for overcoming difficulties and dangers that would daunt others, that someone described as niggardly is attracting obloquy for being too careful with his money, and so on. There is a circumscribed range of inputs and outputs. And this is how it has to be, for we have to know the kind of thing, at the 'subjacent' [descriptive] level, to retail in order to engage someone's will when we are prescribing courses of action. (Blackburn 1998, pp. 102-103; also 1981, p. 180 on the benefits of inculcating and acquiring descriptively shapeful concepts)

A way of avoiding TCA can be glimpsed here that has not, as far as I know, been given any attention in metaethical debates surrounding thick concepts. The concepts that are shapeless according to Blackburn - 'funny', 'gross', 'divine' - are not concepts that obviously qualify as G-members. A non-cognitivist may reject $\mathrm{P} 4$ by arguing that there are no thick concepts that are shapeless but genuine. This move allows the non-cognitivist to hold on to the Hare's conception of moral rationality, while granting that Theo may not be able to master the extension of some thick concepts (that are not G-members). With this move, two kinds of thick concepts are created: the thick genuine concepts whose extensions Theo can master and the thick pseudo-concepts whose extensions Theo cannot master, which are mere means of "sounding off".

What supports the claim that most or all thick concepts have shape? To explain the moral judgements of an agent we must, if we are Galilean naturalists, assume that different judgements are the outcome of different natural features that the agent confronts (Blackburn 1981, pp. 168-169). If thick concepts do not have shape then it appears that we cannot explain how moral agents acquire and use thick concepts within a naturalistic framework. This may be a mere appearance though. Jonathan Dancy (1998) has argued that connectionist models of cognition and prototype theories of concepts show that it is at least possible that a natural moral agent can master the extension of a

14 Blackburn 1998, p. 96 on 'fat $\downarrow$ ' and "pejorative racial slurs", pp. 99-100 on 'cruel', pp. 102-103 on 'courageous'. 
shapeless concept. ${ }^{15}$ Nevertheless, we should expect that teaching and learning a shapeful concept is less costly than teaching and learning one without shape, and hence that most concepts have shape (Blackburn 1981, p. 180).

\section{Conclusion}

I have attempted both to present a charitable interpretation of TCA, and, to some extent, assess the argument's impact. My explication of the argument makes it clear that it is not only intended to establish that a two-component approach to some thick concepts is untenable on its own, but also to establish that non-cognitivists have to take a two-component approach if they want to construe the application of those thick concepts as genuine (that is, as consistent or as rational). The explication also highlighted, with the introduction of the set $G$, the need to ask which concepts that are descriptively shapeless and which concepts that must be construed as genuine.

By large, I think TCA is unsuccessful against non-cognitivism. It is far from obvious why non-cognitivists must take a two-component approach to thick concepts, and Entanglers have not yet shown convincingly why alternative non-cognitivist approaches fail or is incompatible with other commitments made by non-cognitivists. Non-cognitivists can argue that while there are (or may be) shapeless thick concepts (such as, perhaps, 'funny', 'gross', etc), all the important thick concepts (the G-members, such as, perhaps, 'courageous', 'cruel', etc) do in fact have shape. Alternatively, they may accept that there are "genuine" but shapeless thick concepts and avoid TCA by articulating a conception of moral rationality that is compatible with such shapelessness. Moreover, TCA is far from conclusive even against non-cognitivists who take a two-component approach. TCA rests on a contestable intuition concerning Theo's prospects in ESE, and I do not believe the Entanglers have shown why this intuition is correct (even though I have granted that the burden of proof regarding Theo's prospects is on Disentanglers such as Hare who deny that any concept is naturally shapeless rather than on Entanglers). ${ }^{16}$

Olle Blomberg

olle.blomberg@gmail.com

15 Interesting further explorations of connectionism and moral particularism that take the cue from Dancy can be found in the work of Marcello Guarini $(2005,2006)$.

16 I would like to thank my former supervisor Bo Petersson for his contagious enthusiasm, and the Department of Religion and Culture at Linköpings universitet for financial support. I also want to thank Martin Andersson, Marion Godman, Elijah Millgram, my audience at the GAP.6 conference in Berlin, and two anonymous reviewers. 


\section{References}

Altham, J. E. J. (1986) 'The Legacy of Emotivism'. In: G. McDonald \& C. Wright (eds.): Fact, Science and Morality. Oxford: Blackwell Publishing, pp. 275-88.

Anderson, Elizabeth (1993) Value in Ethics and in Economics. Cambridge, MA: Harvard University Press.

Ayer, Alfred Jules (2001) [1936] Language, Truth and Logic. London: Penguin Books.

Barker, Stephen (2000) 'Is Value Content a Component of Conversational Implicature?'. Analysis 60, pp. 268-79.

Blackburn, Simon (1981) 'Reply: Rule-Following and Moral Realism'. In: S. Holtzman \& C. Leich (eds.): Wittgenstein: To Follow a Rule. London: Routledge, pp. $163-87$.

- (1986) 'Making Ends Meet'. Philosophical Books 27(4), pp. 193-203.

- (1992) 'Through Thick and Thin'. The Aristotelian Society Supplementary Volume 66, pp. 285-99.

- (1998) Ruling Passions: A Theory of Practical Reasoning. Oxford: Clarendon Press.

Burton, Stephen L. (1992) 'Thick Concepts Revised'. Analysis 57, pp. 28-32. Rpt. in: A. Fisher \& S. Kirchin (eds.): Arguing About Metaethics. Routledge, 2006.

Crary, Alice (2002) 'Why Can't Moral Thought Be Everything It Seems?'. Philosophical Forum 33(4), pp. 373-91.

Dancy, Jonathan (1998) 'Can A Particularist Learn The Difference Between Right and Wrong'. In: K. Brinkmann (ed.): Proceedings of the 20th World Congress of Philosophy, Volume 1: Ethics, pp. 59-72.

- (1996) 'In Defence of Thick Concepts'. Midwest Studies in Philosophy 20, pp. 263-279.

Dennett, Daniel C. (1995) 'Intuition Pumps', in: John Brockman(ed.), The Third Culture: Beyond The Scientific Revolution, Simon \& Schuster, New York, pp. 181-197.

Gibbard, Allan (1990) Wise Choices, Apt Feelings: A Theory of Normative Judgment. Oxford: Clarendon Press.

Gibbard, Allan (1992) 'Thick Concepts and Warrant for Feelings'. The Aristotelian Society Supplementary Volume 66, pp. 267-83.

Guarini, Marcello (2005) 'Particularism and Generalism: How AI can Help us to Better Understand Moral Cognition'. In: G. M. Anderson, S. L. Anderson \& C. Arme (eds.): Machine Ethics: Papers from the 2005 Fall Symposium. Technical Report FS-05-06, American Association for Artificial Intelligence, Menlo Park, California, pp. 52-61.

Guarini, Marcello (2006) 'Particularism and the Classification and Reclassification of Moral Cases'. IEEE Intelligent Systems 21(4) (July/August), pp. 22-28.

Hare, R. M. (1963) Freedom and Reason. London: Oxford University Press.

- (1970) [1952] The Language of Morals. London: Oxford University Press.

- (1997) Sorting Out Ethics. Oxford: Clarendon Press. 
Hurley, Susan (1983) 'Objectivity and Disagreement'. In: T. Honderich (ed.): Morality and Objectivity: Essays in Honour of John Mackie. London: Routledge \& Kegan Paul, pp. 54-97.

Jackson, Frank (1999) 'Non-Cognitivism, Validity and Conditionals'. In: D. Jamieson (ed.): Singer and His Critics. Oxford: Blackwell Publishers, pp. 18-37.

Koons, Jeremy R. (2001) 'Emotions and Incommensurable Moral Concepts'. Philosophy 76(4), pp. 585-604.

Lang, Gerald (2001) 'The Rule-Following Considerations and Metaethics: Some False Moves'. European Journal of Philosophy 9(2), pp. 190-209.

Lovibond, Sabina (1983) Realism and Imagination in Ethics. Oxford Basil Blackwell.

Mackie, John (1977) Ethics: Inventing Right and Wrong. Penguin Books.

McDowell, John (1978) 'Are Moral Requirements Hypothetical Imperatives?'. Proceedings of the Aristotelian Society, suppl. vol. 52, pp. 13-29.

- (1979) 'Virtue and Reason'. Monist 62, pp. 331-50.

- (1981) Non-Cognitivism and Rule-Following'. In: S. Holtzman \& C. Leich (eds.): Wittgenstein: To Follow a Rule. London: Routledge, pp. 141-162.

- (1998) Mind, Value, and Reality. Cambridge, MA: Harvard University Press.

Miller, Alexander (2003) An Introduction to Contemporary Metaethics. Cambridge: Polity Press.

Millgram, Elijah (1995) 'Inhaltsreiche ethische Begriffe und die Unterscheidung zwischen Tatsachen und Werten'. In: C. Fehige \& G. Meggle (eds.): Zum moralischen Denken. Frankfurt a. M.: Suhrkamp. An English draft, 'Thick Ethical Concepts and the Fact-Value Distinction' is available at http://content.lib.utah. edu/u?/ir-main, 845 (accessed July 3, 2007).

Putnam, Hilary (2002) The Collapse of The Fact/Value Dichotomy and Other Essays. Cambridge, MA: Harvard University Press, Cambridge.

Smith, Michael (1994) The Moral Problem. Oxford: Blackwell Publishing.

Stevenson, Charles L. (1938) 'Persuasive Definitions'. Mind 47, 187, pp. 331-50.

- (1948): Ethics and Language. New Haven: Yale University Press.

Taylor, Charles (2003) 'Ethics and Ontology'. The Journal of Philosophy 100(6), pp. 305-20.

Van Roojen, Mark (2005) 'Expressivism, Supervenience and Logic'. Ratio (new series) 18, pp. 190-205.

Williams, Bernard (1985) Ethics and the Limits of Philosophy. Cambridge, MA: Harvard University Press.

—(1986) 'Reply to Simon Blackburn'. Philosophical Books 27(4), pp. 203-8. 